\title{
Literally Speaking
}

by Liam McCarthy

The use of the word literally has recently been a source of great controversy as more and more people use the word in a non-literal sense. According to The Oxford English Dictionary, the primary definition of literally is, "In a literal, exact, or actual sense; not figuratively, allegorically, etc." To some, the widespread use of the word literally in a non-literal sense represents a misappropriation of the word that detracts from its original definition. For others, this colloquial use of literally is just part of the growth of the word and our definitions of words should reflect how they are used in everyday conversation. Before looking into the transformation of the word literally, a look at the origin and definition of this word is necessary.

The word literally comes from the addition of the suffix "-ly" to the word literal, a borrowing from the French word literal and the Latin word littera. Both the French and the Latin uses of the word relate to letters of the alphabet or literature, specifically signifying copying texts word-for-word. Literal first appeared in the English language around 1398, and also indicated some relation to letters or literature, with particular emphasis on copying texts letter-for-letter.

Around 1443, the word started to be used in a theological sense to differentiate between the actual text of a religious passage and the spiritual meaning behind the words. This meant that a "literal reading" of the Bible or other sacred texts would examine passages ignoring any symbolic connotations of words. For example, an annotation in the Bible by John Wycliffite from 1450 states that a literal understanding of Jerusalem is that of a city, as opposed to an allegorical understanding of Jerusalem as a holy church. Literally came to represent a reading of the Bible that looked at the exact wording of the text without any outside metaphorical or allegorical interpretation.

This understanding of the word literal to distinguish between customary and symbolic definitions of words in sacred texts soon extended to biblical law. "Literal interpretation" of biblical law entails an emphasis on the actual letter of the law rather than a judgement on the spirit of the law. Importantly, the use of literal to mean word-for-word interpretation created a broader sense of the word than the narrow connotation of letter-for-letter transcriptions that literal had represented in French, Latin, and English before the $15^{\text {th }}$ century. 
Use of literally expanded over the next four hundred years as it started to be used outside of just interpreting religious texts. By at least the late 1600s, literally was used in the way that The Oxford English Dictionary primarily defines it now, as people started to use literally in many different contexts to distinguish the actual meaning of words from the figurative meanings behind them. For example, as early as 1687 , poet and playwright Jonathan Dryden writes, "My daily bread is literally implored", indicating that he was actually begging for food every day. Interestingly, not long after literally entered the secular vocabulary, it was used as a way to exaggerate statements figuratively. In 1769, Francis Brooke wrote in her novel The History of Emily Montague, "He is a fortunate man to be introduced to such a party of fine women at his arrival; it is literally to feed among the lilies." The Oxford English Dictionary lists this use of literally as the first figurative use of the word for the sake of hyperbole. Many popular and well-respected authors used literally in this way, including Charles Dickens, who wrote in 1839 , "[He] had literally feasted his eyes in silence on his culprit", and Mark Twain, who wrote in 1876, "Tom was literally rolling in wealth." With these appearances in popular literature like Nicolas Nickleby and The Adventures of Tom Sawyer respectively, the use of literally in a nonliteral sense gained legitimacy, culminating in its own entry in The Oxford English Dictionary in 1903: "Used to indicate that some (freq. conventional) metaphorical or hyperbolical expression is to be taken in the strongest admissible sense: 'virtually, as good as'; (also) 'completely, utterly, absolutely'." While the dictionary does note that this use of literally is colloquial and not often used in standard or formal English (even though the Twain and Dickens examples seem to prove otherwise), the definition nevertheless remains.

The inclusion of this definition in the dictionary was not met without controversy, however; in 1909, Webster's International Dictionary included this second definition of literally, but in Merriam-Webster's Dictionary on English Usage, the use of literally in a figurative sense was described as a misuse meant to create hyperbole, going as far as to say, "It often appears in contexts where no additional emphasis is necessary."

Not long after, around 1920, lexicographer H.W. Fowler argued that the use of literally in figurative situations was a grave misuse of the word that diminishes honesty in our language. This debate has only increased in recent years as literally is continually "misused" in popular culture. While many critics like to condemn popular sitcoms, talk shows, or reality shows for making use of the hyperbolic literally, some of the most important people in the world are not above using literally to exaggerate claims in their statements, as evidenced by Joe Biden's rampant use of the word in a speech at the 2012 Democratic National Convention. Notable lines like, "The 
American people literally stood on the brink of depression" and "President Obama had an unyielding faith in the capacity and the capability of our special forces, literally the finest warriors in the history of the world", are just two of ten examples of his use of the word in this speech alone. Another reason this debate has gained traction in recent years is the recognition of the more controversial definition of literally in an increasing number of dictionaries, such as Google's dictionary, Macmillan Dictionary, and The Cambridge Dictionary. The debate over the inclusion of the colloquial definition of literally highlights a larger debate between prescriptivists and descriptivists. Prescriptivists argue that allowing this second definition of literally makes using the word confusing, as this definition seems to allow for literally meaning both in a literal sense, and the opposite, in a figurative sense. Descriptivists are quick to refute this argument, however, pointing out our use of words like sanction, which means to allow, but also to forbid. They argue that this is simply how our language grows over time and that the dictionary should reflect a common use of the word, even if this use seems to contradict its original intended use. Descriptivists also point out that most dictionaries' goals are to note how English should be used as well as to make note of how English is used. Katherine Martin, head of U.S. dictionaries at Oxford University Press states, "We serve a dual purpose: to help people compose text and to help people understand text. We wouldn't be doing our job if we didn't provide definitions of words as they are actually used."

Whether or not one believes that dictionaries should prescribe or describe the way words are used, the growth of the word literally is remarkable. What once referred simply to copying a text letter-for-letter has now become a staple in the popular lexicon, with use steadily increasing since 1912. This increased popularity has led literally to becoming the crux of a debate that has lasted over a hundred years now and does not seem to be slowing down. While grammar aficionados may not appreciate the popularity of the extended definition of literally, the word's history of use and "misuse" over hundreds of years by notable authors and public figures cannot be ignored as controversy continues to surround this word.

\section{Works Cited}

Baron, D. (2010). A literal paradox: "literally" generally means 'figuratively' OUPblog.

Brooke, Francis. (1769). The History Of Emily Montague. OED

Coleman, Dana. (2013). According to the dictionary, "literally" now also means "figuratively". Salon. 
Dryden, Jonathan. (1687). Hind \& Panther. OED

"Literally." Google Ngram Viewer.

"literally, adv.", "literal, adj. and n." OED Online. Oxford University Press.

"Literally." Merriam-Webster. Merriam-Webster.

Muther, Christopher. (2011). Literally, the most misused word. Boston.com. The New York Times.

Rollins, Samantha. (2013). How the wrong definition of 'literally' sneaked into the dictionary. The Week.

Skurie, Jaclyn. (2013, August 18). The literal truth about the word "literally." National Geographic. National Geographic Society.

Transcript: Vice President Biden's Convention Speech. (2012). NPR.

Twain, Mark. (1876). The Adventures of Tom Sawyer. OED

Wilton, Dave. (2013). Literally. Wordorigins.org.

Wycliffite, John. (1450). Prol. Old Test. Bible. OED 